\title{
Analysis of Commission Forensic-medical Examinations performed in Cases Concerning the Responsibility of Surgical Professional Doctors
}

\author{
Natalia Kozan, Volodymyr Voloshynovych“, Yuliia Kotsyubynska, Halyna Zelenchuk, \\ Andrii Tsikhivskyi
}

\begin{abstract}
The objective of the research was the analysis of the structure of the commission of forensic medical examinations concerning professional offenses of medical professionals of the surgical profile according to the data of the Ivano-Frankivsk Regional Bureau of Forensic Medical Expertise for the period 2015-2019.

Materials and methods. The material of the study were the annual reports of the Ivano-Frankivsk Regional Bureau of Forensic Medical Expertise (Commission Department) and criminal case materials. Obtained data were processed using Microsoft Exel, Statistica 6.0.

Results. It was found that forensic medical examinations in case of improper performance of professional duties by medical workers accounted for a relatively small part $71(14.3 \%)$ of the total forensic medical expertise. After the performed analysis, it was found that the doctors made diagnostic, therapeutic, organizational-tactical, deontological and combined errors that had a direct $(29 \%)$ or indirect $(26 \%)$ connection with the onset of death or adverse effects on the patient's health. In $45 \%$ of cases, there was no correlation between the doctor's actions and the occurrence of adverse effects for the patient.

Conclusions. The number of cases for improper performance of professional duties by medical workers is significantly higher in surgeons and obstetricians-gynecologists than in doctors of therapeutic profile. Every year, the complexity of commission forensic medical examinations in case of improper performance of professional duties by medical workers increases. This is due to the increasing complexity of surgical interventions and instrumental examination methods, as well as the increasing legal literacy of the population.
\end{abstract}

\section{Keywords}

forensic examination; offenses of medical workers

Ivano-Frankivsk National Medical University, Ukraine

${ }^{\star}$ Corresponding author: voloshynovych@yahoo.com

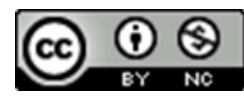

Copyright @Natalia Kozan, Volodymyr Voloshynovych, Yuliia Kotsyubynska, Halyna Zelenchuk, Andrii Tsikhivskyi , 2020

\section{Problem statement and analysis of the latest research}

During the reform of the health care system, there is a growing demand for quality and effective healthcare services. However, every year the number of complaints about doctors' professional misconduct in connection with the development of legal literacy of the population increases. Patients' dissatisfac- tion with medical services is at the heart of criminal and civil proceedings against healthcare professionals $[1,2]$.

Quite often, in the practice of investigating crimes and subsequent criminal proceedings, during a court hearing, there is a need to resolve issues that cannot be answered by one specialist because they do not have all the necessary knowledge. In this case, 


\section{Analysis of Commission Forensic-medical Examinations performed in Cases Concerning the Responsibility of Surgical Professional Doctors - 2/5}

there is a need to conduct such a type of forensic examination as a commission. The peculiarity of this examination is that it is multi-level, complex in nature and usually requires the involvement of specialists in various medical specialties in the expert commission. Today, such expertise is quite broad. Often, this kind of forensic examination becomes a means of proving or refuting the guilt of a suspect and accused of a crime [3].

Despite the relatively small number of commission expertise in comparison with other departments of the Regional Bureau of Forensic Medical Expertise, the department of commission forensic medical examinations, without a doubt, performs a considerable amount of work and is key, because, according to item 3 "Rules for conducting forensic medical examinations in the bureau of forensic examination", commission examinations in the department are performed to eliminate contradictions between previously made examination and other case materials in case of unjustified conclusions or doubts of the person conducts the inquiry, investigator, prosecutor, judge or court in the correctness of the aforementioned examination, as well as to establish the conception period, the ability to fertilize, the percentage of loss of professional capacity and the correctness of medical care in cases of criminal liability upon improper performance of professional duties by medical workers $[4,5]$.

By comparison, medical errors in the UK are the third cause of mortality after diseases of the cardiovascular system and cancer. In the US, medical errors rank fifth among the causes of death, and every 15 minutes, five people die due to the fault of doctors or medical staff [6].

The main problem with the organization of forensic medical examinations in cases of inadequate medical care is the obsolescence of the regulatory framework and its non-compliance with the requirements of today. There is an urgent need to recognize at the legislative level the special status of forensics in cases of offenses in the professional activity of medical professionals. An important problem of medical examinations regarding defects in medical care is their lack of regulation, lack of an officially recognized detailed methodology for performing such examinations, the ambiguity of terms and concepts used in expert and law enforcement practice in clarifying the circumstances of a medical incident. The findings of forensic expert committees do not always meet the necessary objectivity, evidence and scientific validity $[7,8]$.

Objective. To analyze the structure of the commission forensic medical examinations concerning professional offenses of medical professionals of the surgical profile according to the data of the Ivano-Frankivsk Regional Bureau of Forensic Medical Expertise for the period 2015-2019.

\section{Materials and Methods}

The annual reports of the Ivano-Frankivsk Regional Bureau of Forensic Medical Expertise (Commission department). There were studied 71 "Conclusions of Expert", investigators' decisions and court decisions on the appointment of the expertise, medical examination materials regarding the provision of medical assistance and other criminal case materials. The data obtained were processed using Microsoft Exel, Statistica 6.0.

\section{Results and Discussion}

When examining the annual reports of the Commission Department, it was found that in 2015 the 26 (16.7\% of the total commission examinations cases) were performed in cases of offenses in the professional activity of medical professionals, 2 of which $(7.7 \%)$ were for surgeons, $10(38.5 \%)$ for obstetricians and gynecologists, $9(34.6 \%)$ for anesthesiologists, others -5 (19.2\%) (Tables 1, 2).

In 2016, the total number of the commission examination in cases of offenses in the professional activity of the medical professionals was 7 (6.8\% of the total commission examinations), of which only $1(14.2 \%)$ were for surgeons, $2(28.6 \%)$ - obstetricians and gynecologists, $2(28.6 \%)$ - anesthesiologists, $2(28.6 \%)$ - in the affairs of the doctors of other specialties.

In 2017there were performed 20 (20.4\%) commission examination in cases of offenses in the professional activity of medical professionals, among 


\section{Analysis of Commission Forensic-medical Examinations performed in Cases Concerning the Responsibility of Surgical Professional Doctors - 3/5}

Table 1. Comparison of the total number of commissions forensic medical examinations and examination in case of improper performance of professional duties by medical workers performed at the commission department during 2015 - 2019.

\begin{tabular}{ccc}
\hline Year & $\begin{array}{c}\text { Total number of commissions forensic } \\
\text { medical examinations }\end{array}$ & $\begin{array}{c}\text { Examination in case of improper } \\
\text { performance of professional duties by } \\
\text { medical workers, amount }(\%)\end{array}$ \\
\hline 2015 & 156 & $26(16.7 \%)$ \\
2016 & 103 & $7(6.8 \%)$ \\
2017 & 98 & $20(20.4 \%)$ \\
2018 & 55 & $10(18.2 \%)$ \\
2019 & 83 & $8(9.6 \%)$ \\
\hline Total & 495 & $71(14.3 \%)$ \\
\hline
\end{tabular}

Table 2. Structure of the commission forensic medical examinations concerning professional offenses of medical professionals in different specialties during 2015-2019.

\begin{tabular}{lccccc}
\hline Health care worker's specialty & 2015 & 2016 & 2017 & 2018 & 2019 \\
\hline Surgeons & 2 & 1 & 3 & 3 & 1 \\
Obstetricians and gynecologists & 10 & 2 & 4 & 3 & 2 \\
Anesthesiologists & 9 & 2 & 1 & - & 1 \\
Others medical specialties & 5 & 2 & 12 & 4 & 4 \\
\hline Total & 26 & 7 & 20 & 10 & 8 \\
\hline
\end{tabular}

them $3(15 \%)$ - for surgeons, and obstetriciansgynecologists $-4(20 \%)$, anesthesiologists $-1(5 \%)$ and cases of doctors of other specialties $-12(60 \%)$.

In 2018 , the total number of commission examination in cases of offenses in the professional activity of medical professionals were $10(18.2 \%$ of the total commission examinations), of which 3 (30\%) was for surgeons, $3(30 \%)$ - obstetriciansgynecologists, and $4(40 \%)$ - in the affairs of doctors of other specialties.

In 2019, there were performed 8 (9.6\%) commission examination in cases of offenses in the professional activity of medical professionals, among them $1(12.5 \%)$ - for surgeons, and obstetriciansgynecologists - $2(25 \%)$, anesthesiologists $1(12.5 \%)$ and cases of doctors of other specialties $4(50 \%)$.

During the last 5 years, 495 examinations have been carried out in the commission department of Ivano-Frankivsk Regional Bureau of Forensic Medical Expertise. It was found that forensic medical examinations in case of improper performance of professional duties by medical workers accounted for a relatively small part $71(14.3 \%)$ of the total forensic medical expertise.

In all cases, the questions of the correctness of the established diagnosis, the adequacy of the conducted treatment, the timeliness of medical care were raised to decide the forensic medical examination. Most of the examinations also raised the question of the adequacy of the provision of medical care at each stage (emergency medical care, district hospital, regional hospital, etc.).

After the analysis, it was found that the doctors committed diagnostic, therapeutic, organizationaltactical, deontological and combined errors that had a direct $(29 \%)$ or indirect $(26 \%)$ connection with the onset of death or adverse effects on the patient's health. In $45 \%$ of cases, there was no correlation between the doctor's actions and the occurrence of adverse effects for the patient.

Analyzing data from similar studies conducted 
at other regional bureaus $[6,9]$, we can conclude that the frequency and pattern of "medical cases", are independent of the region and are approximately the same.

\section{Conclusions}

1. Forensic medical examinations in case of improper performance of professional duties by medical workers accounted for a relatively small part of the total forensic medical expertise.

2. The frequency of commission forensic medical examinations are determined by the diagnostic, therapeutic, organizational, tactical, deontological and combined errors that have led to the death or adverse health effects of the patient.

3. The number of cases for improper performance of professional duties by surgeons, obstetricians and gynecologists are higher than doctors of therapeutic profile.

4. Every year, the complexity of commission forensic medical examinations in case of improper performance of professional duties by medical workers increases. This is due to the increasing complexity of surgical interventions and instrumental survey methods, as well as the increasing legal literacy of the population.

\section{Conflict of Interest}

The authors stated no conflict of interest.

\section{Financial Disclosure}

The authors declared no financial support.

\section{References}

[1] Pletenetska AO, Mishalov VD, Markov YuI. The current state of the question of forensicmedical aspects of mistakes which arise during providing medical care. Journal "Integrative Anthropology". 2014; 1 (23): 63-67. http: / / nbuv.gov.ua/UJRN/Ia_2014_1_14
[2] Pletenetska A. Results of Analysis of Commission Forensic Medical Examinations of Kyiv City Clinical Bureau of Forensic Medical Examinations upon Improper Performance of Professional Duties by Medical Workers. Galician Medical Journal. 2016; 2 (23): 63-66. http://ojs. ifnmu.edu.ua/index. php/gmj/article/view/539/511

[3] Areshonkov VV. Appointment problems and conducting complex examination during pretrial investigation and legal action criminal proceedings. Juridical psychology.2015; 1: 90-99. http: / / nbuv.gov . ua/UJRN/ urpp_2015_1_11

[4] Hurov OM, Kravchenko YuM, Kis AV, Sapielkin VV, Balanovskyi VV, Serbinenko IY. Legal conflicts and methodological foundations of forensic medical examinations concerning professional offenses of medical workers. The collection of materials of the international conference "Modern achievements in the field of forensic medicine and problematic issues during conducting of forensic examinations in the department of commissions expertise and the department of corps expertise". Lviv.2016; 224$228 \mathrm{p}$.

[5] Khyzhniak VV, Olkhovskyi VO, Morgun AO, Kutsenko KV, Morgun OO. Forensic and medical support of " medical cases". The theory and practice of forensics expertise and criminalistics. 2018; 18: 558-567. DOI: https : / / doi. org/10.32353/khrife.2018.65

[6] Kryvda GF, Plevinskis PV, Kryvda RG, Slusarenko OO, Umanskiy DO. Analysis of the medical care defects on the base of committed forensic-medical commission examinations in Odessa region during 2011-2015. Achievements in biology and medicine. 2016; 1: 45-48.

[7] Franchuk VV. Forensic medical examination in cases of medical malpractice: problematic issues of its performance. Bukovinian Medical Herald. 2019; 23 (2): 130-135. 
DOI: https://doi.org/10.24061/ 2413-0737.XXIII.2.90.2019.52

[8] Franchuk VV, Kalyniuk NM, Zozulia VM, Kalyniuk BM. Peculiarities of Questions, Foreseen by Resolutions on Appointment of Forensic-Medical Examination in Cases of Violations of Professional Duties by Medical Professionals. Medical Law. 2017; 2: 7183. DOI: https://doi.org/10.25040/ medicallaw2017.02.071

[9] Shandyga-Glushko O, Kozitska N, Kryazheva O. Analysis of commission forensic expertise cases conducted in affairs of bringing medical workers to the responsibility. Forensic- medical expertise. 2015; 2: 95-100. http: //nbuv. gov.ua/UJRN/sme_2015_2_15

Received: 2020-03-31

Revised: 2020-05-05

Accepted: 2020-06-05 